\title{
FİBRÖZ DİSPLAZİ: DERLEME
}

\section{FIBROUS DYSPLASIA: REVIEW}

\author{
Arş. Gör. Dt. Muhammed Enes NARALAN* \\ Arş. Gör. Dt. Furkan CANTÜRK*
}

\author{
Prof. Dr. Fatma ÇAĞLAYAN* \\ Arş. Gör. Dt. Esin AKOL GÖRGÜN*
}

\author{
Makale Kodu/Article code: 4033 \\ Makale Gönderilme tarihi: 03.04.2019 \\ Kabul Tarihi; 11.12.2019 \\ DOI : $10.17567 /$ ataunidfd.658046
}

\author{
Muhammed Enes Naralan: ORCID ID: 0000-0002-2444-4322 \\ Fatma Çağlayan: ORCID ID: 0000-0002-0666-8824 \\ Furkan Cantürk: ORCID ID: 0000-0002-7968-6855 \\ Esin Akol Görgün: ORCID ID: 0000-0002-6711-7188
}

\section{ÖZ}

Fibröz displazi (FD), normal kemik dokusunun fibröz dokuyla yer değiştirmesi sonucu oluşan fibro-osseoz bir lezyondur. Vücutta kraniyofasiyal kemiklerde olabileceği gibi diğer kemiklerde de görülebilir. FD, tek bir kemikte tutulum gösteriyorsa monostotik fibröz displazi (MFD), birden fazla kemikte tutulum gösteriyorsa poliostotik fibröz displazi (PFD) adını almaktadır. Ayrıca genel sistemik etkileri olan McCune-Albright sendromunun (MAS) bir komponenti olarak da görülebilmektedir. Tedavisinde, takipten cerrahi rezeksiyona kadar birçok yol izlenebilmektedir. Bu makalede FD'nin etiyolojisi, klinik davranışları, histopatolojisi, radyolojik özellikleri, ayırıı tanısı ve tedavisi hakkında detaylı bilgi verilmiştir.

Anahtar kelimeler: Fibröz displazi, McCune-Albright Sendromu, Monostotik fibröz displazi, Poliostotik fibröz displazi

\section{ABSTRACT}

Fibrous dysplasia (FD) is a fibro-osseous lesion caused by the replacement of normal bone tissue with fibrous tissue. It can be seen in craniofacial bones in the body or in other bones. If FD shows involvement in a single bone, monostotic fibrous dysplasia (MFD) is referred to as polyostotic fibrous dysplasia (PFD), if it shows involvement in more than one bone. It can also be seen as a component of McCune-Albright syndrome (MAS) with general systemic effects. In the treatment, many paths can be followed up from follow-up to surgical resection. In this article, detailed information about etiology, clinical behavior, histopathology, radiological features, differential diagnosis and treatment of FD are given.

Key Words: Fibrous Dysplasia, McCune-Albright Syndrome, Monostotic Fibrous Dysplasia, Polyostotic Fibrous Dysplasia

*Atatürk Üniversitesi Diș Hekimliği Fakültesi Ağız, Diș ve Çene Radyolojisi AD, Erzurum.

Kaynakça Bilgisi: Naralan ME, Çağlayan F, Cantürk F, Akol Görgün E. Fibröz Displazi: Derleme . Atatürk Üniv Diş Hek Fak Derg 2020; 30: 312-319 Citation Information: Naralan ME, Caglayan F, Canturk F, Akol Gorgun E. Fibrous Dysplasia: Review. J Dent Fac Atatürk Uni 2020; 30: 312-319

\section{GİRIŞ}

Fibröz displazi (FD), normal kemik dokusunun fibröz dokuyla yer değiştirmesi sonucu oluşan fibroosseoz bir lezyondur. ${ }^{1,2}$ İlk olarak 1891 yılında Von Recklinghausen ${ }^{3}$ tarafından raporlanmıştır ve 1938 yılında Lichtenstein tarafından tarif edilmiştir. FD insidansı $1 / 4000-1 / 10000$ arasındadır. ${ }^{4}$ FD olguları bütün kemik tümörlerinin $\% 2,5^{\prime}$ ini, benign kemik tümörlerinin ise $\% 7^{\prime}$ sini oluşturmaktadır. ${ }^{5}$

FD özellikle kraniyofasiyal kemikler başta olmak üzere insan vücudundaki birçok kemiği tutabilir. Asemptomatik olarak görülebileceği gibi birçok komplikasyon ve semptomlara da neden olabilir. Meydana gelebilecek komplikasyonlar, fonksiyonel bozukluklar ya da estetik deformiteler şeklinde olabilir. FD, benign bir lezyon olmasına rağmen nadir de olsa agresif seyir gösteren vakalara da rastlanılmıştır. ${ }^{6-8}$ Etiyolojisi tam olarak bilinmese de hamartoz olduğu düşünülmektedir. Son yıllarda yapılan çalışmalar neticesinde genetik mutasyonlar sonucu oluşabileceği konusunda kuvvetli deliller ortaya çıkmıştır. ${ }^{9}$

FD'nin 3 tipi bulunmaktadır. Bunlar; Monostotik Fibröz Displazi(MFD), Poliostotik Fibröz displazi(PFD) ve McCune-Albright Sendromu (MAS) ile görülen tipidir. Sadece kraniyofasiyal kemiklerde tutulum görülmesi durumunda "Kraniyofasiyal Fibröz Displazi" terimi de kullanılmaktadır. ${ }^{10}$ Tek bir kemikte tutulum varsa monostotik fibröz displazi(MFD), birden fazla kemikte tutulum varsa poliostotik fibröz displazi(PFD), 
endokrinal problemlerle konjenital bir şekilde görülüyorsa McCune-Albright Sendromu (MAS) denilmektedir. Bu tiplerden en sık görüleni $\% 70$ oranla MFD'dir. ${ }^{4}$ Bunların dışında Lee ve ark. ${ }^{11}$ durgun (büyüme olmayan), nonagresif (yavaş büyüyen) ve agresif (hızlı büyüme gösteren ve parastezi görülen) tipler olarak da sınıflandırmışlardır. ${ }^{11}$

\section{Klinik Özellikler}

FD, genellikle çocuklarda ve genç yetişkinlerde ortaya çıkmaktadır. ${ }^{1}$ Hastalık, izole olarak tek bir kemiği tutabildiği gibi tüm iskeleti tutacak kadar da yaygınlaşabilir. ${ }^{2}$ Çenelerde mandibulaya kıyasla maksillada daha sık görüldüğü belirtilmiştir. ${ }^{1,12}$ Valentini ve ark. $^{13}$ ise FD nin 2. dekatta ve zygoma-maksiller komplekste daha sık görüldüğünü ifade etmişlerdir. FD'nin semptomatik hastalarda, ortalama 5 yaşında ${ }^{2}$, kraniyofasiyal tutulumun gözlemlendiği hastalarda ise $\% 90$ oranla 3.4 yaşında fark edildiği bildirilmiştir. ${ }^{14}$ Özellikle lokal agresif FD'nin ekseriyetle genç hastalarda fark edildiği ortaya konmuştur. ${ }^{6}$ FD'nin görüldüğü vakaların \%31'inin hem maksillayı hem de mandibulayı tuttuğu gözlemlenmiştir. ${ }^{15}$

FD, tutulumun olduğu bölgede ağrısız, yavaş büyüyen ve unilateral şişlikler şeklinde ortaya çkabilir. ${ }^{1}$ ${ }^{2}$ FD'nin bazen kemik suturlarını geçerek büyümesine devam ettiği de fark edilmiştir. Bu şekilde tutulumun gözlemlendiği kemikler arasında; maksilla, sfenoid, temporal, frontal, oksipital, parietal kemikler sayılabilir. ${ }^{2,16} \mathrm{Bu}$ nedenle maksillada görülen vakalar orta suturu geçerek karşı maksillada da tutulum gösterebilir. ${ }^{2}$ FD, femurun proximalini tutarak "shepherd's crook" olarak anılan deformiteyi meydana getirir. 2, 17 MFD; femur, tibia, kraniyofasiyal kemikler ve kostalarda da görülebilmekle beraber en nadir olarak vertebralarda görülür. ${ }^{1}$

MFD, genellikle asemptomatik olduğundan dolayı tesadüfen rutin dental muayenede çenelerde fark edilmekte olup, vakaların \%80'inin 15 yaşından önce tespit edildiği belirtilmiştir. ${ }^{17,} 18$ Poliostotik tip, genellikle 10 yaşından önce ve kadınlarda daha sık görülmektedir. ${ }^{19}$ PFD, MFD'ye göre daha agresif ve geniş bir tutulum göstermekte ve semptomları daha belirgin olmaktadır. ${ }^{19}$ MFD, \% $10-30$ oranında kraniyofasiyal kemik tutulumu gösterirken, PFD \% 90-100 oranında kraniyofasiyal kemik tutulumu gösterir. 1, 2, 10, ${ }^{20}$ Fakat şunu belirmekte fayda vardır ki; MFD, PFD'nin öncüsü değildir. Yani MFD görülen hastalar zamanla PFD'ye dönüşmez. ${ }^{16}$ Bundan dolayı PFD'nin konjenital olduğu düşünülmektedir. ${ }^{16}$
MAS, PFD ile beraber deride sütlü kahve lekeleri, erken puberte, hipertiroidi, hipofiz adenomu, Cushing sendromu gibi endokrin anomalilerin görüldüğü sendromdur. ${ }^{21}$ PFD hastalarının \% 3'ünün MAS'a sahip olduğu bildirilmiştir. ${ }^{8}$ 17, 22 MAS'da embriyolojik üç germ tabakası etkilendiğinden deri, yumurtalık, tiroid, adrenal bez ve hipofiz bezlerinde problemler görülmektedir. ${ }^{18} \mathrm{Bu}$ sebeple endokrinopatiler görülür. ${ }^{17,23}$ Hastalarda tiroid lezyonlarının neden olduğu hipertiroidizim görülebilir. ${ }^{17}$ Hipofiz bez problemleri sebebiyle akrogemali de meydana gelebilir. ${ }^{17,23-25}$

Hastalık kadınlarda erkeklerden 10 kat daha fazla görülür. Özellikle puberte dönemindeki kadınlarda sık rastlanılmaktadır. ${ }^{8}$ MAS hastalarında konjenital sütlü kahve lekelenmeleriyle beraber kadın çocuk hastaların \% 80'inde erken puberte görülür. 2, 17, 26, 27 Sütlü kahve lekelenmeleri MAS'da hastalarda genellikle ilk semptom olarak ortaya çıkmaktadır. ${ }^{2}$ Bunlara ek olarak meydana gelen ovarian kistler sonucunda rekürrent vajinal kanamalar, büyüme plaklarının erken kapanması sonucunda iskelet immaturasyonu ve boy kısalığı izlenebilir. ${ }^{26}$ Çoğu erkek çocuk hastada testis tutulumu görülse bile erkeklerde erken puberteye nadiren rastlanmaktadır. ${ }^{26}$

Bilindiği üzere Nörofibramotoziste de sütlü kahve tarzında renklenmeler görülebilmektedir. MAS'da görülen sütlü kahve lekelerinin neurofibramatoziste görülen lekelerden farkı bunların daha düzensiz olmalarıdır. 2,17,19,27 Bazı vakalarda da endokrin bozukluk olmadan yalnızca PFD ve sütlü kahve lekeleri görülebilir. Bu durum da "Jaffe-Lichtenstein Sendromu" olarak anılmaktadır. ${ }^{23}$

Genellikle MFD hastaları asemptomatik, PFD hastaları ise semptomatik olmaktadır. ${ }^{8}$ Ağrı yaygın ve ilk görülen semptomdur ve yaşla beraber artmaktadır. 17 Ağrılı hastalarda ise büyümenin durmasıyla ağrılar da durabilmektedir. ${ }^{18}$ Bazı durumlarda meydana gelen mikrofraktürler, komplet veya inkomplet fraktürler sonucunda da ağrı olabilmektedir. ${ }^{19}$ Fakat bazen de herhangi bir sebebe bağlı olmadan yalancı enflamasyonlu kemik ağrıları oluşabilir. ${ }^{17}$

FD'nin büyümesi kemiğin büyümesinin durmasıyla durur. ${ }^{2,13}$ Fakat bazı durumlarda büyüme durduğu halde lezyon büyüyebilmektedir. 2,8,13,28 Ayrıca hamilelik dönemindeki kadınlarda ve östrojen terapisi alan hastalarda lezyonlarda boyut artışı olduğu tespit edilmiştir. ${ }^{17-19}$ Ek olarak doğumdan sonra ağrı ve fraktür ihtimalinin arttığından da bahsedilmektedir. ${ }^{18,19}$

FD hastalarında tutulumun olduğu bölgeye göre; skolyozis ${ }^{2}$, bölgesel veya yaygın deformite ${ }^{2,10,19}$, 
kemik fraktürü $2,5,29$, ağrı $2,10,19,29$, fonksiyon bozuklu$\mathrm{ğu}^{2,10}$, görme problemleri ${ }^{1,8,10,18}$ gibi komplikasyonlar görülebilmektedir. Sfenoid ve ethmoid kemikleri tutması halinde göz küresinin yeri değişebilmekte ve hastalarda ekzoftalmi görülebilmektedir. ${ }^{6,17}$ Bu nedenle sfenoid kemikte FD tutulumu varsa hastanın gözlerinin de dikkatlice muayene edilmesi gerekmektedir. ${ }^{2}$ Temporal kemikte tutulum olması halinde ise duyma problemleri meydana gelebilir. ${ }^{1,18}$ Maksilla tutulumu sonucunda burun tıkanıklığı ve kalıcı sinüzit komplikasyonlara dâhil olabilir. ${ }^{1}$ Fakat maksiller sinüs içerisinde tutulum yapması durumunda sinüs formunun değişmeyeceği söylenmektedir. ${ }^{30}$

FD nadiren Mazabroud Sendromu (intramuskuler miksomalarla beraber PFD)'nun bir komponenti olarak da görülebilir fakat bu sendrom oldukça nadirdir. ${ }^{4,5,19}$ Mazabroud sendromu, yumuşak dokuda meydana gelen baskıyla semptom vermektedir., 19

Çenelerde görüldüğünde, hastalarda meydana gelen ekspansiyon, dişlerin okluzyonunu etkiler. ${ }^{2}$ FD hastalarının dental durumu ile ilgili olarak dentin displazisi, taurodontizm, odontomalar ve yüksek çürük insidansı görülmüştür. ${ }^{15}$ Sürmemiş dişlerde, kök rezorbsiyonları olabilmektedir. ${ }^{31-33}$ Ek olarak dişlerde yer değişiklikleri meydana gelebilir. ${ }^{10}$ Yeri değişmiş dişler maksiller sinüs içerisine konumlanabilir. ${ }^{1}$

FD, kistik dejenerasyonlara sebebiyet verebileceği belirtilmiştir. ${ }^{16,}{ }^{34}$ FD hastalarında artmış vaskülarizasyon görülebildiğinden hemorajik kemik kistlerine rastlanabilir. ${ }^{18}$ FD'den anevrizmal kemik kisti meydana geldiğini gösteren raporlar mevcuttur. ${ }^{16,34,35}$ FD vakalarının \%1'nin sarkomaya dönüştüğü bildirmiştir. 2,6,22,23,36-40 MAS'da malign dönüşüm \% 4 iken, diğer tiplerde bu oranın $\% 0,5$ olduğu bildirmiştir. ${ }^{5,} 23,28$ Daha önce radyasyon terapisi almış olan hastalarda sarkomaya dönüşme intimali normal hastalardan 400 kat daha fazladır. ${ }^{23}$

\section{Radyolojik Özellikler}

FD teşhisinde konvansiyonel radyogramlar, Manyetik Rezonans Görüntüleme (MRG), Bilgisayarlı Tomografi (BT), Konik Işınlı Bilgisayarlı Tomografi (KIBT) ve sintigrafi gibi radyolojik teknikler kullanımaktadır. $^{8}$

BT, FD'nin teşhis ve tedavisi için önemlidir. ${ }^{1}$ Yapılan çalışmalarda BT'nin FD'nin tanısında kullanılan en etkin yöntem olduğu belirtilmiştir. ${ }^{30,41,42}$ Ayrıca BT'nin en ideal cerrahi zamanın belirlenmesinde ve hastalığın ilerleyişinin takibinde de kullanılabileceği ifade edilmiştir. ${ }^{43}$
Radyolojik incelemede BT ve KIBT ilk tercih edilen tekniklerdir. KIBT'nin FD'nin radyolojik karakteristiklerini BT'den daha detaylı gösterdiği bildirilmiştir. Kochanowski ve ark. KIBT'nin, konvansiyonel bir radyogramdan elde edilen ön tanıyı takiben, hastalığın varlığını ve tutulumunu netleştirmek için gereken yöntem olduğunu belirtmişlerdir. ${ }^{44}$ KIBT, submilimetrik izotropik vokselleri sayesinde sert dokuların yüksek uzaysal çözünürlüğe sahip üç boyutlu görüntülerini verir (Şekil 1 ve 2) ve lezyonun önemli anatomik yapılarla olan ilişkisinin medikal BT'ye göre çok daha düşük radyasyon dozu ve yüksek çözünürlükle incelenmesine olanak sağlar.

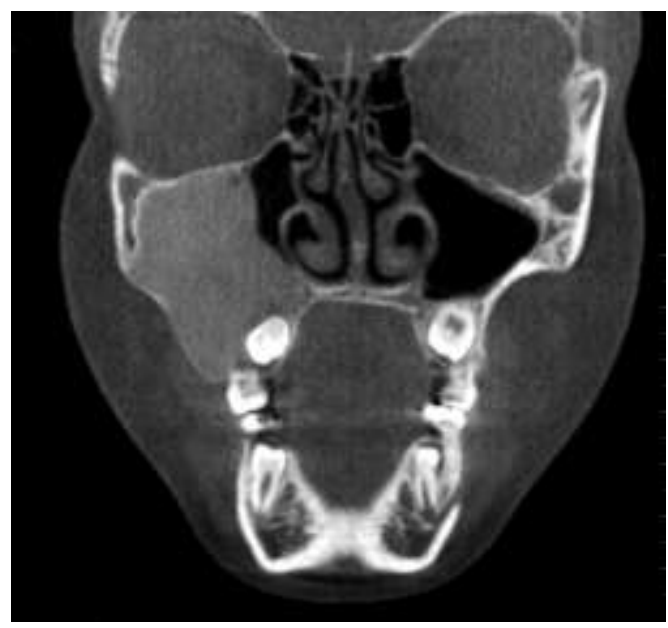

Şekil 1. Koronal KIBT maksillada sağ tuber ve sinüs bölgesinde monostotik fibröz displazi tutulumu.

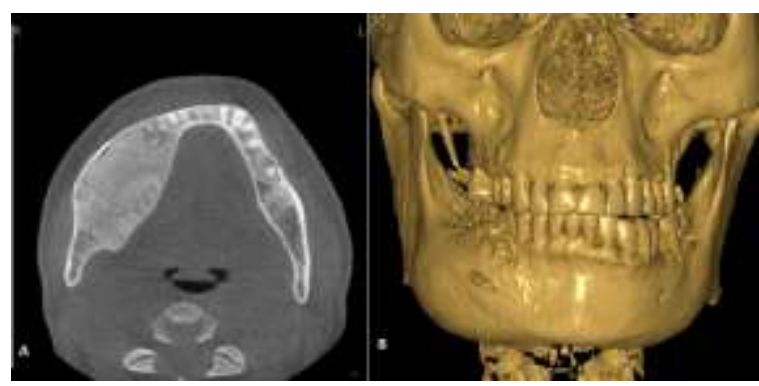

Şekil 2 (A-B). Mandibulada Monostotik Fibröz Displazi A: Aksillar KIBT kesitinde buzlu cam opasifikasyonu bukkolingual ekspansiyon B: Aynı hastanın 3D rekonstrüksiyonun da asimetri ve ekspansiyon izlenmektedir.

FD'nin radyografik görünümü lezyonun safhasına ve lokalizasyonuna bağlı olarak değişik şekillerde olabilir. Radyografide erken safhasında litik olarak izlenen FD lezyonu, ilerleyen safhalarda radyoopak görüntü vermektedir. ${ }^{1}$ Erken dönem FD hastalarında litik alan iyi sınırlı veya kötü sınırlı olarak multilokuler

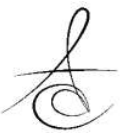


veya unilokuler olarak izlenebilmektedir. ${ }^{23}$ Bazı vakalarda sklerotik marjin de bulunabilmektedir. ${ }^{20}$ FD lezyonları; litik lezyon ${ }^{6,45}$, buzlu cam ${ }^{2,6,17,20,23,30,34}$, granüler $^{1}$, portakal kabuğu ${ }^{1,23}$, atılmış pamuk 1,2,23,34, amorf kütleler ${ }^{1}$ ve parmak izi paterni ${ }^{1,23,34}$ olmak üzere çok değişik şekillerde görüntü verebilir. Bu konuda yapılan çalışmalarda FD'nin BT de \% 56 oranında buzlu cam ,\% 23 oranında homojen görüntü,\% 21 oranında kistik görüntü verdiği bildirilmiştir. ${ }^{1,46-50}$ Yazarlara göre çoğu durumda radyografide görülen buzlu cam görüntüsü tanı koymak için yeterli olmaktadır. ${ }^{2}$ Genç hastalardaki buzlu cam görünümü, ilerleyen dönemlerde heterojen görüntüye dönüşebilmektedir. ${ }^{2}$ Yaşlı ve bisfosfanat kullanan hastalarda ise lezyon etrafında sklerotik saha bulunabilmektedir. ${ }^{2}$

FD'nin ilerleyen dönemlerinde görülen kalsifikasyonlar "duman bulutu" şeklinde olabilir. ${ }^{51} \mathrm{Bu}$ kalsifikasyonlar arttıkça lezyon daha da heterojen bir görünüm almaktadır. ${ }^{51}$ FD'de kartilagöz kalsifikasyonlar da izlenebilir ve bu görüntüler "patlamış mısır" şeklinde görüntü verir. ${ }^{19,51}$

FD hastalarının periapikal filmlerinde ise etkilenmeyen bölgedeki dişlere kıyasla etkilenen bölgedeki dişlerin lamina duraları daha zor seçilmektedir. ${ }^{2,30}$ (Şekil 3) Ayrıca etkilenen mandibular kanal bölgesinde kanalın kortikal duvarları zor seçilir veya kanal yeri değişmiş olarak görülebilir. 2, 30

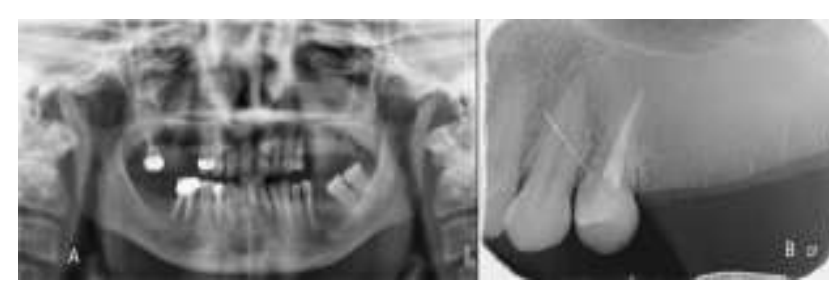

Şekil 3 (A-B):Fibröz Displazide buzlu cam opasifikasyonu A:Fibröz displazinin sol maksiller premolar-molar bölgedeki panoramik radyogramdaki görüntüsü. B: Aynı hastadaki fibröz displazinin periapikal radyogram görüntüsü, sol üst 1 . Premolar kök yüzeyinde lamina dura ve periodontal aralık takip edilemiyor.

FD, radyolojik incelemelerde kortikal kemikte incelmeyle beraber sıklıkla bukko-lingual ekspansiyona neden olabilir. ${ }^{2,} 30$ FD genellikle kemik medullasından başlayıp ${ }^{51}$ kortekse doğru ilerlemektedir. Lezyon kemik korteksini inceltmekteyken ${ }^{17}$ endosteumda skallop tarzında marjinler oluşturabilmektedir. ${ }^{51}$ FD ince kemiklerde daha hızlı yayılım gösterirken, ${ }^{1,23}$ kalın kemiklerde daha yavaş büyümekte ve radyolüsent görüntü vererek kemikte kavitasyonlar meydana getirebilmektedir. ${ }^{1,23}$

FD'de görülen radyopak görüntüler bazen kafatası ve maksillofasiyal kemiklerde Paget hastalığına benzer şekilde atılmış pamuk görüntüsü verebilir. ${ }^{17}$ Ayrıca FD’nin çoğu kraniyomaksillofasiyal kemikleri tutması halinde "aslan yüz" görünümü de meydana gelebilir. ${ }^{28}$

FD'lerde kortikal kemik yıkımı ve yumuşak doku ekspansiyonu malign bir transformasyon olmadığı taktirde oldukça nadir görülür. ${ }^{6}$ Böyle bir durumda malign transformasyon veya anevrizmal kemik kisti dönüşümü ihtimali düşünülmelidir. ${ }^{6,16}$

$F D, M R G$ 'de ise tümör benzeri görüntü verir ve diğer tekniklere göre daha geniş görülmektedir. ${ }^{1,}{ }^{51} \mathrm{X}$ ışını kullanan tekniklerde görülen lezyon etrafındaki sklerotik hat, MRG'de hipointens olarak görülür. ${ }^{51}$ MRG'de T1 sekanslarda hipointens ve iskelet kasına göre izointens ${ }^{51,52}$, T2 sekanslarda ise heterojen, hiperintens, hipointens ve izointens görüntü verebilmektedir. ${ }^{6,17,51}$ Eğer FD'de kistik dönüşüm varsa T2 görüntülerde su yoğunluğu artacağından dolayı hiperintens görüntü izlenir. ${ }^{19}$ Fakat bu görüntüler hastalığa özgü görüntüler değildir. ${ }^{6}$ MRG görüntüleri lezyonun benign veya malign olup olmadığını anlamak için istenebilmektedir. ${ }^{53}$ Ayrıca MRG, malign dönüşüm varsa yumuşak dokuyu etkileyip etkilemediği ve agresif kemik yıkılımı varlığının araştırılması için kullanılabilmektedir. ${ }^{19}$ Sonuç olarak FD'nin MRG'de karakteristik özellikler göstermediği söylenilebilir. ${ }^{51}$ Kontrastlı MRG teknikleri ise agresif FD potansiyelinin incelenmesi için istenilebilir. $^{53}$

Genellikle radyolojik tetkiklerin teşhis için yeterli olduğu söylenmektedir. ${ }^{8}$ Fakat görüntülerdeki çeşitlilikten ve ayırıcı tanıda düşünülmesi gereken diğer patolojilerden dolayı vakalarda kesin tanı için histopatolojik inceleme yapılması gerektiği de belirtmiştir. ${ }^{8,17,53}$ Panoramik grafi, BT ve KIBT ile elde edilen bulgular FD için karakteristik olmasına rağmen, bu bulguların her zaman hastalığa özel birer bulgu olmayabileceği ifade edilmiştir. ${ }^{54}$ Ek olarak sintigrafi, FD hastalarında genellikle PFD'yi elemek için istenmektedir. ${ }^{8}$

\section{Histopatolojik ve Laboratuvar Bulguları}

FD'nin iskelet hücreleri üzerinde etkilerinin olduğu bilinmektedir. FD'nin içerisindeki fibrotik elementlerin histopatolojik yapıları değişkenlik göstermektedir. ${ }^{1}$ Bazı araştırmacılar FD'nin embriyolojik 
dönemde kemik maturasyonunda ki problemden kaynaklandığını söylemektedir. ${ }^{16}$ FD'de görülen kemik rezorpsiyonunun interlokin- 6 artışı nedeniyle meydana gelen osteoklast aktivasyonu sonucu oluştuğu bulunmuştur. ${ }^{18,20}$ Yapılan çalışmalarda kemik rezorbsiyonunun yanında normal kemik iliğinin de osteofibröz dokuyla yer değiştirdiği ifade edilmiştir. ${ }^{18}$

Histolopatolojik inceleme tanı koymada altın standart olarak görülmektedir. ${ }^{20}$ Rımınuccı ve ark. ${ }^{55}$ mikrosokopik incelemelerde 3 farklı patern olduğundan söz etmektedirler. Bunlar; aksillar ve apendiküler iskelette çin yazısı şeklinde görülen, kraniyal kemiklerde sklerotik/Pagetoid patern şeklinde görülen ve çenelerde sklerotik/hipersellülar patern şeklinde görülen tiplerdir. ${ }^{55,56}$

FD hastalarında gen mutasyonlarına da rastlanılmıştır. Şöyle ki; FD'de görülen GNAS mutasyonunun tanı koymada altın standart olduğu düşünülmektedir. ${ }^{2}$ GNAS-1 geninde oluşan mutasyon sonucu preosteoblastlarda meydana gelen değişim ve proliferasyon ile birlikte FD'nin oluştuğu ortaya konmuştur. ${ }^{1,2,5,8,18,23,27}$

Fibroblast büyüme faktörü 23 (FGF 23) artışından dolayı FD hastalarının idrarlarında fosfat bulunabilmektedir. ${ }^{2,18,27} \mathrm{Bu}$ sebeple hastalarda hipofosfatemiye bağlı olarak raşitizm ve osteomalasia da gelişebilmektedir. ${ }^{18,23,57}$ Kontrol altında olmayan hipofosfatemi hastalarında kırık, ağrı ve deformite oluşma ihtimali daha da artmaktadır. ${ }^{58}$ Bunlara ek olarak FD'li hastalarda serum alkalen seviyesinin yükselmesine rağmen kalsiyum, paratiroid hormon seviyesi, 25-hydroksivitamin D, 1,25-dihydroksivitamin D seviyeleri normal olarak bulunmuştur. ${ }^{59}$

\section{Ayırıcı Tanı}

Ayırıcı tanıda; santral dev hücreli granülom ${ }^{1}$, ameloblastik fibrom ${ }^{1}$, ossifiying fibroma ${ }^{1}$, osteosarkom² $^{2}$ osteoblastoma ${ }^{2}$, metastatik kemik tümörü², nonossifiye fibrom ${ }^{22}$, anevrizmal kemik kisti ${ }^{22}$, düşük dereceli santral osteosarkom ${ }^{22}$ dikkate alınmalıdır.

\section{Tedavi}

FD hastalarında tedavi lezyona göre değişir. ${ }^{8}$ Genellikle cerrahi tedavi lokal kontur düzeltme şeklinde yapılır fakat agresif FD görülürse cerrahi tedavi lokal rezeksiyona kadar gidebilmektedir. ${ }^{28}$ Yapılan araştırmalar sonucunda büyüme çağında cerrahi tedaviyle çıkarılan lezyonların \%50'sinde nüks görüldüğü bildirilmiştir. ${ }^{17,18,60,61}$ Eachempati ve ark. ${ }^{7}$ cerrahi tedavinin puberte bitene kadar ertelenmesini tavsiye etmişlerdir. Ayrıca, FD hastalarının ameliyat sonrası ömür boyu takip edilmeleri gerektiği bildirilmiştir. ${ }^{1,50,62}$
Asemptomatik lezyonlar bir süre takip edilebilirler $^{19,63}$ Fakat Cehn ve ark. ${ }^{63}$ FD'nin frontal, orbital, zygomatik ve üst maksiller segment kemiklerini tutması halinde, semptom veya deformite olmasa dahi cerrahi olarak tedavi edilmesi gerektiğini belirtmişlerdir. ${ }^{63}$ Ayrıca, semptomatik lezyonlar, başarısız olmuş diğer tedavi seçenekleri ve malign dönüşüm gösteren lezyonlar da cerrahi olarak tedavi edilmelidirler. ${ }^{19}$

Ağrılı hastalarda parasetamol ${ }^{18}$, nonsteroid antienflamatuar ağrı kesiciler ${ }^{18,29}$, narkotik analjezikler $^{18,29}$, bifosfonatlar ${ }^{8,18,23,29}$ ve kortikosteroidler ${ }^{8}$ kullanılabilir. Bunlara ek olarak paratiroid hormon analog$\mid a r{ }^{22}$, kalsiyum ve Vitamin-D takviyeleri de kullanılabilmektedir. ${ }^{18,23}$

Bifosfonat tedavisi, litik lezyonların dolmasıyla beraber kortikal kalınlık artışı sağlamaktadır. Özellikle generalize vakalarda kullanılabileceği bildirilmiştir. ${ }^{18,19,23}$ Bunlara ek olarak bifosfonat tedavisi alan hastalarda ağırının hafiflediği görülmüştür. ${ }^{20}$ Yasuoka ve ark. kalsitonin tedavisiyle olgunlaşmamış kemiklerde kalsifikasyonu artırarak cerrahi tedaviye hazırlık yapılabileceğini söylemişlerdir. ${ }^{64}$

Sonuç olarak asemptomatik FD vakalarında, lezyon BT ve KIBT de tesadüfen bulunduysa ve takiplerde herhangi bir büyüme ve semptom göstermiyorsa ilk etapta cerrahi tedavi düşünülmemeli ve hasta takip altında tutulmalıdır. ${ }^{65}$

NOT: Calışmada herhangi bir yazar, kurum ya da kurulus ile çıkar çatışması içerisinde bulunmamaktadır. Makale daha önce hiçbir yerde yayınlanmamış ve yayınlanmak üzere işlem görmemektedir

\section{KAYNAKLAR}

1. Gupta D, Garg P, Mittal A. Computed Tomography in Craniofacial Fibrous Dysplasia: A Case Series with Review of Literature and Classification Update. Open Dent J 2017;11:384-403.

2. Burke $A B$, Collins MT, Boyce AM. Fibrous dysplasia of bone: craniofacial and dental implications. Oral Diseases 2017;23:697-708.

3. von Recklinghausen F. Die fibrose oder deformierende Ostitis, die Osteomalacic und die osteoplastische Carcinose, in ihren gegenseitigen Beziehungen. Rudolf Virchow Festschriften. 1891:1-89.

4. Yılmaz HB, Akbulut S, Demir MG, Başak K. Baş-Yüz Fibröz Displazileri. Journal of Kartal Training \& Research Hospital/Kartal Egitim ve Arastirma Hastanesi Tip Dergisi. 2016;27: 1. 
5. Lietman SA, Levine MA. Fibrous dysplasia. Pediatr Endocrinol Rev. 2013;10 Suppl 2:389-96.

6. Muthusamy S, Subhawong T, Conway SA, Temple HT. Locally aggressive fibrous dysplasia mimicking malignancy: a report of four cases and review of the literature. Clin Orthop Relat Res 2015; 473:742-50.

7. Eachempati $P$, Aggarwal $H$, Shenoy V, Baliga $M$. Multidisciplinary approach for management of a patient with fibrous dysplasia of maxilla. BMJ Case Rep 2015;2015.

8. Adetayo OA, Salcedo SE, Borad V, Richards SS, Workman $A D$, Ray $A O$. Fibrous dysplasia: an overview of disease process, indications for surgical management, and a case report. Eplasty. 2015;15:e6.

9. Seçgin CK, Günhan Ö, Gülşahı A. Benign fibroosseöz lezyonlar. Acta Odontologica Turcica. 2016;33:95-101.

10. Ashrafi SK, Asim, Khambaty Y, Suhail Z. Fibrous dysplasia of mandible. J Coll Physicians Surg Pak 2012;22:728-9.

11. Lee J, FitzGibbon E, Chen Y, Kim H, Lustig L, Akintoye SO, et al., editors. Clinical guidelines for the management of craniofacial fibrous dysplasia. Orphanet J Rare Dis; 2012: BioMed Central.

12. Sekerci AE, Sisman Y, Ertas ET, Sahman H, Etöz M, Nazlim S. Fibröz Displazi/Fibrous Dysplasia: Case Report. Turkiye Klinikleri Dishek Bil Derg 2012;18:203.

13. Valentini V, Cassoni A, Marianetti TM, Terenzi V, Fadda MT, Iannetti G. Craniomaxillofacial fibrous dysplasia: conservative treatment or radical surgery? A retrospective study on 68 patients. Plast Reconstr Surg 2009;123:653-60.

14. Hart ES, Kelly MH, Brillante B, Chen CC, Ziran N, Lee JS, et al. Onset, progression, and plateau of skeletal lesions in fibrous dysplasia and the relationship to functional outcome. J Bone Miner Res 2007;22:1468-74.

15. Akintoye SO, Lee JS, Feimster T, Booher S, Brahim J, Kingman A, et al. Dental characteristics of fibrous dysplasia and McCune-Albright syndrome. Oral Surg Oral Med Oral Pathol Oral Radiol Endod 2003;96(3):275-82.

16. Jhamb A, Mohanty S, Jhamb PA. Craniofacial fibrous dysplasia. J Oral Maxillofac Pathol 2012;16:465-9.
17. Chapurlat RD, Orcel P. Fibrous dysplasia of bone and McCune-Albright syndrome. Best Pract Res Clin Rheumatol 2008;22:55-69.

18. Florez $\mathrm{H}$, Peris $\mathrm{P}$, Guanabens N. Fibrous dysplasia. Clinical review and therapeutic management. Med Clin (Barc) 2016;147:547-53.

19. Parekh SG, Donthineni-Rao R, Ricchetti $E$, Lackman RD. Fibrous dysplasia. J Am Acad Orthop Surg 2004;12:305-13.

20. Ren K, Lan T, Yu Z, Chen Y, Tian CQ, Gu HS, et al. Monostotic fibrous dysplasia of the thoracic spine: A case report. J Back Musculoskelet Rehabil 2016;29:387-91.

21. Günhan Ö. Oral ve Maksillofasiyal Patoloji. istanbul: Quintessence Yayıncılık Tanıtım Paz. ve Dış tic. Ltd. Şti; 2015.

22. Riddle ND, Bui MM. Fibrous dysplasia. Arch Pathol Lab Med. 2013;137(1):134-8.

23. Kruse A, Pieles U, Riener MO, Zunker C, Bredell MG, Gratz KW. Craniomaxillofacial fibrous dysplasia: a 10-year database 1996-2006. $\mathrm{Br}$ J Oral Maxillofac Surg 2009;47:302-5.

24. Albright F, Butler AM, Hampton AO, Smith $P$. Syndrome characterized by osteitis fibrosa disseminata, areas of pigmentation and endocrine dysfunction, with precocious puberty in females: report of five cases. New England J Med 1937;216:727-46.

25. Bell NH, Avery S, Johnston CC, Jr. Effects of calcitonin in Paget's disease and polyostotic fibrous dysplasia. J Clin Endocrinol Metab 1970; 31:283-90.

26. Boyce AM, Chong WH, Shawker TH, Pinto PA, Linehan WM, Bhattacharryya $\mathrm{N}$, et al. Characterization and management of testicular pathology in McCune-Albright syndrome. J Clin Endocrinol Metab 2012;97:E1782-90.

27. Akintoye SO, Boyce AM, Collins MT. Dental perspectives in fibrous dysplasia and McCuneAlbright syndrome. Oral Surg Oral Med Oral Pathol Oral Radiol 2013;116:e149-55.

28. Ozek C, Gundogan H, Bilkay U, Tokat C, Gurler T, Songur E. Craniomaxillofacial fibrous dysplasia. J Craniofac Surg 2002;13:382-9.

29. Chapurlat RD, Gensburger D, Jimenez-Andrade JM, Ghilardi JR, Kelly M, Mantyh P. Pathophysiology and medical treatment of pain in fibrous dysplasia of bone. Orphanet J Rare Dis 2012; 7:S3. 
30. Sontakke SA, Karjodkar FR, Umarji HR. Computed tomographic features of fibrous dysplasia of maxillofacial region. Imaging Sci Dent 2011; 41:23-8.

31. Mohan RP, Verma S, Gupta N, Ghanta S, Agarwal $\mathrm{N}$, Gupta S. The radiological versatility of fibrous dysplasia: An 8-year retrospective radiographic analysis in a north Indian population. Indian J Dent 2014;5:139-45.

32. Tabrizi R, Ozkan BT. Craniofacial fibrous dysplasia of orbit. J Craniofac Surg 2008;19:1532-7.

33. Abdelkarim A, Green R, Startzell J, Preece J. Craniofacial polyostotic fibrous dysplasia: a case report and review of the literature. Oral Surg Oral Med Oral Pathol Oral Radiol Endod 2008;106:e49-55.

34. Punyani SR, Srivastava S, Jasuja VR. Craniofacial fibrous dysplasia Report of a case with diverse radiological spectrum. Clinical cases in mineral and bone metabolism : the official journal of the Italian Society of Osteoporosis, Mineral Metabolism Skeletal Diseases 2016;13:249-52.

35. Ferretti C, Coleman $H$, Dent M, Altini M. Cystic degeneration in fibrous dysplasia of the jaws: a case report. Oral Surg Oral Med Oral Pathol Oral Radiol Endod 1999;88:337-42.

36. Qu N, Yao W, Cui X, Zhang H. Malignant transformation in monostotic fibrous dysplasia: clinical features, imaging features, outcomes in 10 patients, and review. Medicine (Baltimore). 2015; 94:e369.

37. Sadeghi SM, Hosseini SN. Spontaneous conversion of fibrous dysplasia into osteosarcoma. J Craniofac Surg 2011;22:959-61.

38. Ruggieri $\mathrm{P}$, Sim FH, Bond JR, Unni KK. Malignancies in fibrous dysplasia. Cancer. 1994;73:1411-24.

39. Yabut SM, Jr., Kenan S, Sissons HA, Lewis MM. Malignant transformation of fibrous dysplasia. A case report and review of the literature. Clin Orthop Relat Res 1988:281-9.

40. Chapurlat RD. Medical therapy in adults with fibrous dysplasia of bone. J Bone Miner Res. 2006;21 Suppl 2:P114-9.

41. Chong VF, Khoo JB, Fan Y-F. Fibrous dysplasia involving the base of the skull. American J Roentgenol 2002;178:717-20.
42. Tehranzadeh J, Fung $Y$, Donohue $M$, Anavim A, Pribram HW. Computed tomography of Paget disease of the skull versus fibrous dysplasia. Skeletal Radiol 1998;27:664-72.

43. Lambert PR, Brackmann DE. Fibrous dysplasia of the temporal bone: the use of computerized tomography. Otolaryngol Head Neck Surg 1984; 92:461-7.

44. Kochanowski NE, Badry MS, Abdelkarim AZ, Lozanoff S, Syed AZ. Radiographic Diagnosis of Fibrous Dysplasia in Maxilla. Cureus 2018; 10:e3127.

45. Çakur B, Durna D, Bilge O, Yıldırım E. Fibröz Displazi: Bir Olgu Sunumu. Atatürk Üniv Diş Hek Fak Derg 2014;24:1-3.

46. Dobre MC, Fischbein N. 'Do not touch'lesions of the skull base. J Med Imaging Radiat Oncol 2014;58:458-63.

47. Guruprasad Y, Prabhakar C. Craniofacial polyostotic fibrous dysplasia. Contemp Clin Dent 2010;1:177-9.

48. Speight PM, Carlos R. Maxillofacial fibro-osseous lesions. Curr Diagn Pathol. 2006;12(1):1-10.

49. Chen YR, Chang CN, Tan YC. Craniofacial fibrous dysplasia: an update. Chang Gung Med J 2006; 29:543-9.

50. Posnick JC. Fibrous dysplasia of the craniomaxillofacial region: current clinical perspectives. Br J Oral Maxillofac Surg 1998;36: 264-73.

51. Shah ZK, Peh WC, Koh WL, Shek TW. Magnetic resonance imaging appearances of fibrous dysplasia. Br J Radiol. 2005;78(936):1104-15.

52. Jee WH, Choi KH, Choe BY, Park JM, Shinn KS. Fibrous dysplasia: MR imaging characteristics with radiopathologic correlation. AJR Am J Roentgenol 1996;167:1523-7.

53. Cappabianca S, Colella G, Russo A, Pezzullo M, Reginelli $A$, Iaselli $F$, et al. Maxillofacial fibrous dysplasia: personal experience with gadoliniumenhanced magnetic resonance imaging. Radiol Med 2008;113:1198-210.

54. Atali O, Pekiner F, Varol A, Dumlu A, Ozbayrak S, Alatli $C$. Radiological and histological observation in a woman patient of fibrous dysplasia 2012. $193 \mathrm{p}$. 
55. Riminucci M, Liu B, Corsi A, Shenker A, Spiegel AM, Robey PG, et al. The histopathology of fibrous dysplasia of bone in patients with activating mutations of the Gs alpha gene: sitespecific patterns and recurrent histological hallmarks. J Pathol. 1999;187:249-58.

56. Cohen MM, Jr., Howell RE. Etiology of fibrous dysplasia and McCune-Albright syndrome. Int J Oral Maxillofac Surg. 1999;28:366-71.

57. Boyce AM, Bhattacharyya N, Collins MT. Fibrous dysplasia and fibroblast growth factor-23 regulation. Curr Osteoporos Rep. 2013;11:65-71.

58. Leet AI, Chebli C, Kushner $\mathrm{H}$, Chen CC, Kelly MH, Brillante $\mathrm{BA}$, et al. Fracture incidence in polyostotic fibrous dysplasia and the McCuneAlbright syndrome. J Bone Miner Res 2004; 19:571-7.

59. Bland LI, Marchese MJ, McDonald JV. Acute monocular blindness secondary to fibrous dysplasia of the skull: a case report. Ann Ophthalmol 1992;24:263-6.

60. Mohan H, Mittal P, Mundi I, Kumar S. Fibrous dysplasia of bone: a clinicopathologic review. Pathol Lab Med Int 2011;3:31-42.

61. Stanton RP, Ippolito E, Springfield D, Lindaman L, Wientroub $S$, Leet $A$. The surgical management of fibrous dysplasia of bone. Orphanet J Rare Dis 2012;7:S1.

62. Ricalde $\mathrm{P}$, Horswell BB. Craniofacial fibrous dysplasia of the fronto-orbital region: a case series and literature review. J Oral Maxillofac Surg 2001;59:157-67; discussion 67-8.

63. Chen YR, Noordhoff MS. Treatment of craniomaxillofacial fibrous dysplasia: how early and how extensive? Plast Reconstr Surg 1990; 86: 835-42.

64. Yasuoka T, Takagi N, Hatakeyama D, Yokoyama K. Fibrous dysplasia in the maxilla: possible mechanism of bone remodeling by calcitonin treatment. Oral Oncol. 2003;39(3):301-5.

65. Canitezer G, Gunduz K, Ozden B, Kose H. Monostotic fibrous dysplasia: A case report. Dent 2012;3:2-4.

\section{Yazışma Adresi}

Muhammed Enes NARALAN

Atatürk Üniversitesi Diş Hekimliği Fakültesi Ağız, Diş ve Çene Radyolojisi Anabilim Dalı 25240 Erzurum/Türkiye

Telefon: +905345449177

E-posta adresi: menaralan@gmail.com 